\title{
Performance comparison of precipitation strategies for recovering succinic acid from carob pod-based fermentation broths
}

\section{Paulina Abigail Sosa-Fernández \& Svetlozar Velizarov}

To cite this article: Paulina Abigail Sosa-Fernández \& Svetlozar Velizarov (2018)

Performance comparison of precipitation strategies for recovering succinic acid from carob pod-based fermentation broths, Separation Science and Technology, 53:17, 2813-2825, DOI: 10.1080/01496395.2018.1473881

To link to this article: https://doi.org/10.1080/01496395.2018.1473881

\section{Published online: 16 May 2018.}

Submit your article to this journal $\sqsubset$

山 Article views: 291

Q View related articles ¿

View Crossmark data $₫$

Citing articles: 1 View citing articles \ulcorner 


\title{
Performance comparison of precipitation strategies for recovering succinic acid from carob pod-based fermentation broths
}

\author{
Paulina Abigail Sosa-Fernández and Svetlozar Velizarov 두 \\ LAQV-REQUIMTE, Department of Chemistry, Faculty of Science and Technology, Universidade NOVA de Lisboa, Caparica, Portugal
}

\begin{abstract}
Experiments were performed for comparing and selecting the most appropriate precipitation strategy for succinic acid (SA) recovery from carob pod extract fermentation broths. The performances of three downstream options - employing calcium hydroxide, magnesium hydroxide or ammonia - were investigated and compared from operational, techno-economical and sustainability viewpoints. The highest SA recovery (84.3\%) was obtained with ammonia, whereas the calcium-based treatment proved inadequate. Sustainability indicators favoured magnesium-based treatment, closely followed by the ammonia-based one. A preliminary economic analysis favours magnesium-based treatment, which appears to be the most feasible option. However, materials recycling and possible by-products commercialization could well position also ammonia-based treatment.
\end{abstract}

ARTICLE HISTORY

Received 12 February 2018

Accepted 3 May 2018

\section{KEYWORDS}

Succinic acid recovery; precipitation; carob pod; fermentation broth

\section{Introduction}

Succinic acid (SA), a saturated four-carbon dicarboxylic acid, can be produced via two routes: petrochemical and biological. While the petrochemical route is based on the chemical transformation of maleic anhydride, the biological route makes use of a variety of microorganisms, including bacteria and yeasts, to ferment natural carbohydrates, thus offering several advantages such as the possibility of obtaining diverse platform chemicals from renewable resources ${ }^{[1-3]}$ with a lower net fossil energy consumption. ${ }^{[4]}$ Because of this, SA has been recognized as one of the most promising building block molecules that can be derived from natural sources. ${ }^{[5-7]}$

To provide conditions for large-scale SA bioproduction, current research has been focused on three main areas: 1) screening and improvement of SAproducing microorganisms, including metabolically engineered strains; ${ }^{\left[{ }^{8-10]}\right.}$ 2) optimization of the fermentation process operation; ${ }^{[11]}$ and 3) use of different types of prospective feedstocks. ${ }^{[12-14]}$ Referring to this last category, SA production by A. succinogenes $130 Z$ using carob pod water extracts as a feedstock was recently reported. ${ }^{[15]}$ The carob tree (Ceratonia siliqua L.) is a Mediterranean perennial tree that produces pods containing seeds $(10 \% \mathrm{w} / \mathrm{w})$ and a highly rich sugar pulp $(90 \% \mathrm{w} / \mathrm{w})$, which may constitute as much as $50 \%$ of the carob pod mass. ${ }^{[16]}$ Although the worldwide carob pod production accounts for almost 400,000 tons/year, a large portion of this is discarded since it is considered a by-product of the carob locust bean gum industry. Thus, carob pod represents a promising feedstock for the bio-industry. Indeed, the volumetric productivity of $1.67 \mathrm{~g} \mathrm{SA} / \mathrm{L} \mathrm{h}$ achieved by Carvalho et al. when using a carob pod extract as substrate $^{[17]}$ is one of the highest available in the literature regarding bacteria-based fermentations, ${ }^{[18]}$ which justifies the interest in further researching this SA production method.

Equally important as achieving a high SA productivity during the fermentation step is to develop an efficient downstream process, which allows one to recover the SA obtained in a useful form. Owing to the large variety of SA biosynthetic conditions that can be applied, the type and sequence of recovery steps need to be adapted to address the removal of particular impurities; therefore, no universal solution exists. Because of this, downstream processing has been found to be the most economically demanding part of the SA production process, accounting for $50-80 \%$ of the associated costs. ${ }^{[7,19]}$

As for other carboxylic acids, the first SA downstream processing method that was developed involves precipitation of its carboxylate anion with calcium. According to the patent by Datta et al., ${ }^{[20]}$ calcium hydroxide is added to the fermentation broth in order

CONTACT Svetlozar Velizarov velizarov@fct.unl.pt E LAQV, DQ - Office 4.26, FCT, UNL, 2829-516 Caparica, Portugal.

Present address: Wetsus, European Centre of Excellence for Sustainable Water Technology. P.O. box 1113, 8900 CC Leeuwarden, The Netherlands Color versions of one or more of the figures in the article can be found online at www.tandfonline.com/lsst.

(c) 2018 Council of Scientific and Industrial Research, Govt. of India 
to neutralize it and, at the same time, precipitate the produced SA as calcium succinate. This intermediate product is filtered off from the fermentation broth and then treated with concentrated sulphuric acid, thus generating calcium sulphate (gypsum) as a by-product in an equimolar amount. Free SA is obtained by ionexchange chromatography, after which the product is further concentrated and crystallized by evaporation. Although relatively high SA yields can be obtained through this method, the consumption of reactants that cannot be regenerated or recycled is high, which increases the process costs. In addition, some authors suggest that the by-product, calcium sulphate, is not likely to be commercialized because of smell and colour impurities. ${ }^{[21]}$ Thus, the process has raised concerns regarding its economic and environmental impactrelated aspects. ${ }^{\text {[22] }}$

Several other possible SA recovery techniques have been proposed and studied. These include membrane filtration, ${ }^{[19,23,24]}$ vacuum distillation, ${ }^{[2]}$ liquid-liquid extraction, ${ }^{[25]}$ salting-out extraction, ${ }^{[26]}$ direct crystallization $^{[27,28]}$ and electrodialysis ${ }^{[11,29]}$ among others. Yet, most of them have only been tested on a laboratory scale. However, since some companies and consortia have now begun to implement largescale bio-based SA productions, it becomes important to evaluate which SA recovery technique(s) is(are) the most feasible one(s).

Currently, there are four known commercial bio-SA producers: BioAmber, Reverdia, Myriant and Succinity. ${ }^{[2,30]}$ Among them, BioAmber and Reverdia have each developed and commercialized yeast processes to produce $\mathrm{SA}$, which use a minimal amount of base for $\mathrm{pH}$ control, thus leaving most of the carboxylic acids present in their acidic forms. As a consequence, the steps needed to recover the SA in a purified form are minimized compared to bacteria-based fermentations. ${ }^{[30]}$ The other two companies, Succinity and Myriant, have indeed patented bacteriabased fermentations. And, quite interestingly, it has been suggested that the downstream processes that they most likely will implement are those based on precipitationinvolving schemes. ${ }^{[2,30]}$ Presumably, Succinity is (will be) employing a magnesium hydroxide-based precipitation process, whereas Myriant will be making use of ammonia, to precipitate the succinate during fermentation. ${ }^{[2,31]}$

Both precipitation processes are relatively similar, besides the difference in employing either magnesium or ammonia as a cation to precipitate the succinate. The magnesium-based precipitation, patented by de Haan et al., ${ }^{[32]}$ employs magnesium hydroxide (or another magnesium-containing species, e.g., magnesium carbonate) for $\mathrm{pH}$ control during fermentation, resulting in the accumulation of magnesium succinate as the main fermentation product. After biomass separation, hydrochloric acid is added to convert the obtained magnesium succinate into a free SA, producing magnesium chloride as a by-product.

Similarly, an SA precipitation method with ammonia has been patented. ${ }^{[33,34]}$ In the scheme proposed by Yedur et al., di-ammonium succinate needs to be obtained, either by using an ammonium cation-based material to maintain neutral $\mathrm{pH}$ in the fermenter or by substituting the ammonium cation for the cation of the succinate salt formed in the fermenter. After biomass separation, diammonium succinate is converted into a free SA and diammonium sulphate by the addition of sulphuric acid. For both schemes, the resulting SA is separated from the by-product by precipitation (after a concentration step) and subsequently further purified if required.

The use of two different precipitation techniques in newly developed industrial processes is worthy of attention. Therefore, this study was conducted with the objective of experimentally investigating and comparing the performance of three precipitation-based downstream options for the specific case of carob pod-based fermentation broth. The comparison includes not only the downstream operational aspects, but also preliminary techno-economical and sustainability considerations.

\section{Experimental}

\section{Materials}

Fresh SA-containing broth was obtained from batch fermentations using carob pod water extracts as a carbon source and Actinobacillus succinogenes $130 \mathrm{Z}$ as an SA-producing strain, as described by Carvalho et al. ${ }^{[15]}$ The fermentations were carried on a $1 \mathrm{~L}$ benchtopbioreactor with a working volume of $900 \mathrm{~mL}$, sparged with $\mathrm{CO}_{2}$ at $0.05 \mathrm{vvm}$, at $37^{\circ} \mathrm{C}$, and stirred at $250 \mathrm{rpm}$. The carob pod aqueous extracts were obtained through the procedure described in. ${ }^{[15]}$ The culture medium contained per litre $10.0 \mathrm{~g}$ yeast extract, $8.5 \mathrm{~g}$ of $\mathrm{NaH}_{2} \mathrm{PO}_{4} \cdot \mathrm{H}_{2} \mathrm{O}, 15.5 \mathrm{~g}$ of $\mathrm{K}_{2} \mathrm{HPO}_{4}$ and $12.6 \mathrm{~g}$ of $\mathrm{NaHCO}_{3}$, and during the fermentation process, $5 \mathrm{M}$ $\mathrm{NaOH}$ solution was added to keep the $\mathrm{pH}$ at 6.8. The fermentation broths of two different batches were centrifuged for 15 minutes at $15,300 \mathrm{~g}$ to remove the cells, recovering $1.8 \mathrm{~L}$ of the uniform supernatant solution. The concentrations of SA, methanoic acid (formic, FA) and acetic acid (AA) in the broth were equal to approximately $20.0,14.3$ and $13.3 \mathrm{~g} / \mathrm{L}$, respectively, corresponding to mass fractions of 0.42 for SA, 0.30 for FA and 0.28 for AA. ${ }^{[15]}$

The model solution employed in some experiments included all the components of the culture medium 
(8.5 g of $\mathrm{NaH}_{2} \mathrm{PO}_{4} \mathrm{H}_{2} \mathrm{O}, 15.5 \mathrm{~g}$ of $\mathrm{K}_{2} \mathrm{HPO}_{4}$ and $12.6 \mathrm{~g}$ of $\mathrm{NaHCO}_{3}$ ), along with the three carboxylic acids in the following concentration: SA $20.0 \mathrm{~g} / \mathrm{L}, \mathrm{FA} 14.3 \mathrm{~g} / \mathrm{L}$ and AA $13.3 \mathrm{~g} / \mathrm{L}$.

All inorganic salts (analytical grade), hydrochloric acid (37\% purity) and sulphuric acid (98\% purity) were purchased from Panreac. For the ammonia-based precipitation, ammonia solution $25 \% \mathrm{w} / \mathrm{w}$ (reagent grade) was employed. Roasted carob flour was purchased from a local store. All reagents were employed without further purification.

\section{Precipitation with calcium hydroxide}

The precipitation procedure, schematically presented in Fig. 1a, applied was adapted from Li et al. ${ }^{[27]}$ and performed as follows. First, $\mathrm{Ca}(\mathrm{OH})_{2}$ slurry $(30 \%$, w/v) was slowly added to $100 \mathrm{~mL}$ of acidified supernatant of the fermentation broth. The mixture obtained was vigorously stirred at room temperature until the solution $\mathrm{pH}$ increased to 12.5-13.0. The obtained slurry was immediately filtered through a $0.2 \mu \mathrm{m}$ Whatman filter using a vacuum pump. The filtrate was recovered, and the precipitate was further washed with $50 \mathrm{~mL}$ of distilled water, which was also recovered. Next, the filter cake was re-dissolved in $100 \mathrm{~mL}$ of distilled water, and $\mathrm{H}_{2} \mathrm{SO}_{4}$ concentrated solution (48.15\%, w/v) was added while stirring the mixture at room temperature until the solution $\mathrm{pH}$ decreased to 1.5-2.0. Again, the obtained slurry was filtrated through a $0.2 \mu \mathrm{m}$ Whatman filter using a vacuum pump, the SA-containing filtrate was recovered and the precipitate was washed with distilled water $(50 \mathrm{~mL})$, which was also recovered. The filter cake was then dried at $70^{\circ} \mathrm{C}$ to a constant weight and the weight was registered. The filtrates and the washing water (WW) compositions were analysed by HPLC as described in Analyses section

\section{Precipitation with magnesium hydroxide}

For each of the two experiments performed (see Fig. 1b), $100 \mathrm{ml}$ of the previously homogenized and centrifuged fermentation broth was used as in the $\mathrm{Ca}(\mathrm{OH})_{2}$ precipitation tests (previous section). In one of the experiments (P21), the solution was titrated with $5 \mathrm{M} \mathrm{NaOH}$ to obtain a $\mathrm{pH}$ equal to 6.8 , whereas in the other, the $\mathrm{pH}$ was left unaltered (P22). Then, a defined amount of $\mathrm{Mg}(\mathrm{OH})_{2}$ was added to the solution, which was stirred vigorously. The minimal required amount of $\mathrm{Mg}(\mathrm{OH})_{2}$ necessary to achieve a ratio of $\mathrm{Mg}(\mathrm{OH})_{2}$ to $\mathrm{SA}$ of 1 to $2(\mathrm{w} / \mathrm{w})$ was set, taking into consideration the information provided in De Haan et al. ${ }^{[32]}$ However, since the fermentation broth also contained other acids that could react with $\mathrm{Mg}^{2+}$, higher proportions of this hydroxide were used in the second experiment (1.0 and $2.5(\mathrm{w} / \mathrm{w})$ for P21 and P22, respectively). To solubilize completely the $\mathrm{Mg}(\mathrm{OH})_{2}$ present, the solutions were heated up to $72^{\circ} \mathrm{C}$ while stirring at $300 \mathrm{rpm}$. They were then left to cool down to $50^{\circ} \mathrm{C}$, and concentrated hydrochloric acid (37\%) was added until a $\mathrm{pH}$ of around 1.5 was reached. Since the procedure requires the use of a concentrated solution of magnesium chloride (close to $30 \%(\mathrm{w} / \mathrm{w})$ ), the solutions were left to evaporate in an airflow chamber at room temperature for a time period of 5 days, during which the volumes were monitored. When the solution volumes dropped to below $20 \mathrm{~mL}$ each, crystals had already formed, and the liquid phases were separated from the solids by decantation and stored for later HPLC analyses. The solids were left for one more day in the airflow chamber in order to dry them completely; their solid weights were registered and then re-dissolved in $50 \mathrm{~mL}$ of distillated water at room temperature. Samples of these final solutions were stored for HPLC analyses.

\section{Precipitation with ammonia}

As in the previous cases (see Fig. 1c), $100 \mathrm{ml}$ of the homogenized and centrifuged fermentation broth was employed in two experiments. In one of the experiments (P31), the solution was titrated with $5 \mathrm{M} \mathrm{NaOH}$ to a $\mathrm{pH}$ equal to 6.8, whereas the other was left unaltered (P32). Then, $10 \mathrm{~mL}$ of $25 \%(\mathrm{w} / \mathrm{w})$ ammonia solutions was added to each of the solutions. The amount was determined by titrating the $\mathrm{P} 31$ solution until a $\mathrm{pH}$ of 11 was reached, and for P32 the same volume was employed. Both solutions were agitated vigorously for 10 minutes and then left to evaporate at room temperature in an airflow chamber for two days to obtain a di-ammonium succinate concentration of $25-30 \%(\mathrm{w} / \mathrm{v})$. When the volumes of the solutions had reduced to two-third of the original ones, they were titrated with a $\mathrm{H}_{2} \mathrm{SO}_{4}$ concentrated solution $(48.15 \%$, (w/v)) until a $\mathrm{pH}$ of 1.5 was reached. Then, the solutions were filtered through a $0.2 \mu \mathrm{m}$ Whatman filter using a vacuum pump and left again (for approximately three more days) in an airflow chamber until the volumes dropped below $20 \mathrm{~mL}$ and crystals had formed. The liquid phase was separated from the solids by decantation and stored for later HPLC analyses. The solids were left for one more day in the airflow chamber in order to dry them completely; their weights were registered, and then the solids were re-dissolved in $50 \mathrm{~mL}$ of distillated water at room temperature. Samples of these final solutions were also analysed by HPLC. 


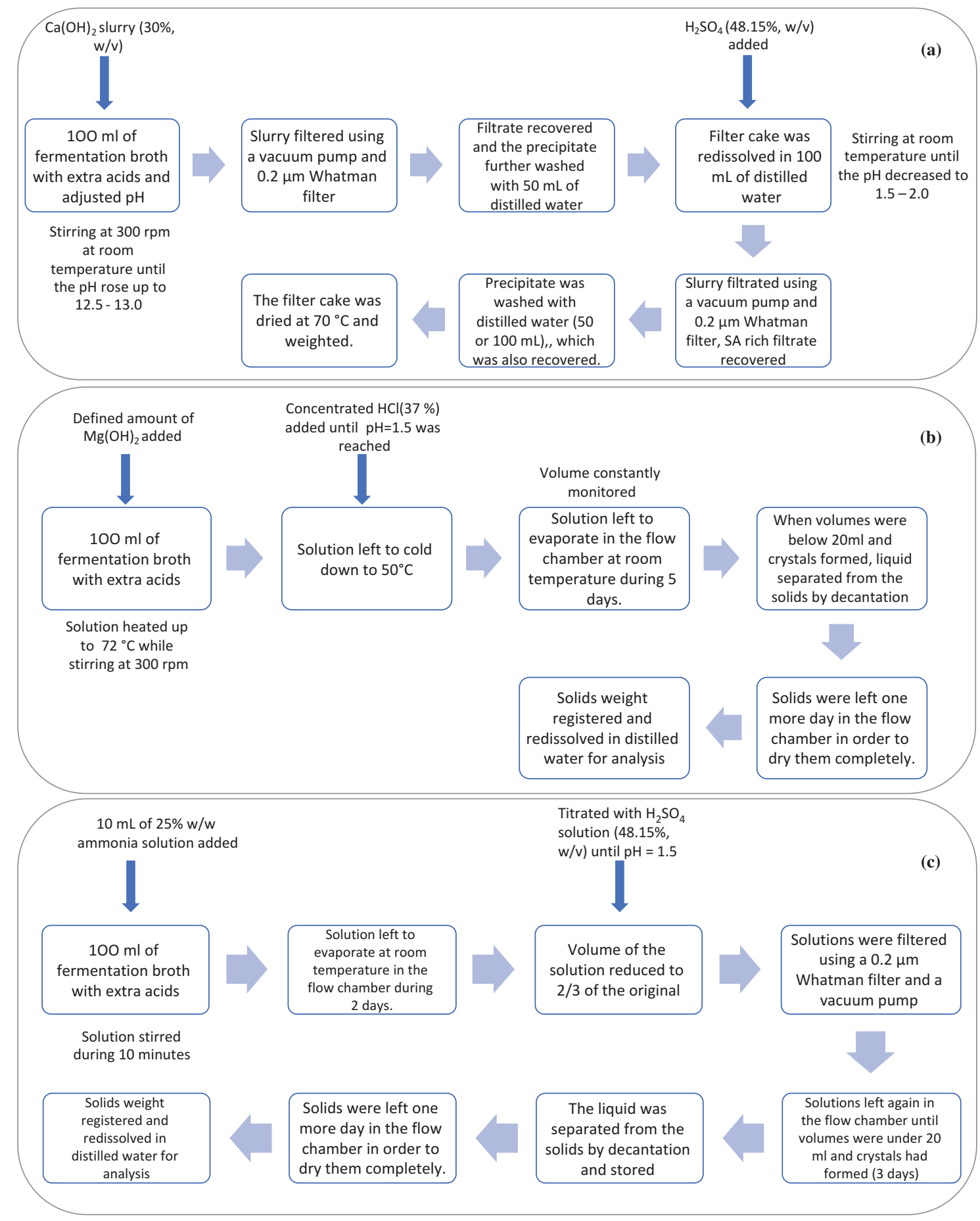

Figure 1. Methodologies of the performed precipitation experiments: a) with calcium hydroxide, $\mathbf{b}$ ) with magnesium hydroxide and $\mathbf{c}$ ) with ammonia solution.

\section{Analyses}

The concentrations of carboxylates (succinate, acetate and carboxylate) in all samples were determined by high-performance liquid chromatography (HPLC) using a Metacarb $87 \mathrm{H}$ column (Varian) and a refractive index detector (RI-71, Merck). The column was eluted at $30^{\circ} \mathrm{C}$ with $0.01 \mathrm{~N} \mathrm{H}_{2} \mathrm{SO}_{4}$ aqueous solution at a flow rate of $0.5 \mathrm{~mL} / \mathrm{min}$. The $\mathrm{R}^{2}$ values of the corresponding calibration curves in all cases were above 0.999 (data not shown). Sugars (glucose, fructose and sucrose) were also analysed by HPLC, at the same operating conditions, but using a Hi-Plex H column (Agilent). ${ }^{[15]}$ The $\mathrm{pH}$ was measured with a commercial $\mathrm{pH}$ meter (Basic 20 from Crison). 


\section{Evaluation of precipitation performance}

The precipitation schemes employed were evaluated and compared in terms of SA recovery and material intensity and waste-related indicators. For SA recovery $(\mathrm{R})$, the following equation was used:

$$
R=\frac{\text { Recovered mass of } S A}{\text { Total mass of SA originally present }}
$$

The material intensity and waste-related parameters of choice were mass intensity (MI) and E-factor (EF) and calculated as the quotient between the waste produced or the total mass used in a process or a process step divided by the mass of the product obtained, ${ }^{[35]}$ defined by Eqs. (2) and (3), respectively.

$$
E F=\frac{\sum^{w} \text { aste mass }}{\sum^{p} \text { roduct mass }}
$$

$$
M I=\frac{\text { Total mass used in a process or process step }}{\text { Mass of final product }}
$$

It should be noted that for the EF factor, the waste mass was defined as everything but the desired product and was estimated as the total amount of waste produced in the process excluding water. A higher EF means more waste and, hence, a greater negative environmental impact. ${ }^{[36]}$

For the economic analysis, the cost in USD per kg of recovered SA was calculated using the following equation:

$$
\text { Cost }=\frac{\sum(\text { Amount of reagent used } \times \text { unit cost })}{\text { SA recovery }}
$$

where the amount of reagent used is given in $\mathrm{kg}$ or $\mathrm{L}$ (depending on the reagent) per litre of fermentation broth, the unit cost is given in USD per kg or L and the SA recovery is given in $\mathrm{kg}$ per litre of fermentation broth.

\section{Results and discussion}

\section{Precipitation with calcium hydroxide}

The main characteristics of the experiments performed are provided in Table 1. Four experiments (P1-P4) were initially carried out using the methodology described in the previous section in order to test the influence of the solution $\mathrm{pH}$ on the process performance in terms of SA, AA and FA recoveries.

According to the procedure, SA should be recovered in the second filtrate, after reaction of calcium succinate with the added sulphuric acid. The recovered masses of the compounds in each step (first filtrate, first WW, second filtrate and second WW) were calculated, and the data obtained was compared. As can be observed in Fig. 2, in all cases, a significant amount of the SA was "lost" already in the first filtrate together with the other two acids. A considerable amount of acids was also present in the first WW. As a consequence, in the second filtrate and second WW, the SA recovery was minimal. Notably, the highest SA recovery in the set of experiments was obtained in experiment $\mathrm{P} 4$, indicating that when sodium and calcium

\begin{tabular}{|c|c|c|c|}
\hline Method & Experiment & Description & $\begin{array}{c}\mathrm{SA} \\
\text { recovery } \\
(\%)\end{array}$ \\
\hline Calcium & P1 & Conditions as described in Section 2.3. & 1.76 \\
\hline \multirow[t]{12}{*}{ hydroxide } & P2 & Same as $\mathrm{P} 1$, but targeted $\mathrm{pH}$ equal to 12 , when adding $\mathrm{Ca}(\mathrm{OH})_{2}$ & 1.74 \\
\hline & P3 & Same as $\mathrm{P} 1$, but targeted $\mathrm{pH}$ equal to 10 , when adding $\mathrm{Ca}(\mathrm{OH})_{2}$ & 0.59 \\
\hline & P4 & Same as $\mathrm{P} 1$, but $\mathrm{pH}$ was not adjusted & 12.52 \\
\hline & P5 & $\begin{array}{l}\text { Used fermentation broth, extra acids were added, no } \mathrm{NaOH} \text { was used. The same amount of } \mathrm{Ca}(\mathrm{OH})_{2}(\text { as in } \mathrm{P} 4) \\
\text { was added. Overnight cooling was performed. The first filtrate was not washed }\end{array}$ & 26.35 \\
\hline & P6 & Same as $\mathrm{P} 5$, but used five times the amount of $\mathrm{Ca}(\mathrm{OH})_{2}$ & 21.01 \\
\hline & P7 & Same as $\mathrm{P} 5$, but used 10 times the amount of $\mathrm{Ca}(\mathrm{OH})_{2}$ & 26.67 \\
\hline & P8 & Same as P7, but pH was adjusted to 6.8 with $5 \mathrm{M} \mathrm{NaOH}$ & 16.50 \\
\hline & P9 & $\begin{array}{l}\text { Used a model solution. No use of } \mathrm{NaOH} \text {. The same amount of } \mathrm{Ca}(\mathrm{OH})_{2} \text { (as in P4) was added. Filtrated } \\
\text { immediately without cooling. No washing of the first filtrate was performed }\end{array}$ & 33.67 \\
\hline & P10 & Same as P9, but left for cooling overnight & 24.08 \\
\hline & P11 & $\begin{array}{l}\left.\text { Fermentation broth with extra acids. Left for shaking } 24 \text { hours at } 37^{\circ} \mathrm{C} \text {. The same amount of } \mathrm{Ca}(\mathrm{OH})_{2} \text { (as in } \mathrm{P} 5\right) \\
\text { was added }\end{array}$ & 28.68 \\
\hline & P12 & Same as $\mathrm{P} 11$, but used five times the amount of $\mathrm{Ca}(\mathrm{OH})_{2}$ & 24.52 \\
\hline & P13 & Same as P11, but performed with a model solution & 23.32 \\
\hline \multirow[t]{2}{*}{$\begin{array}{l}\text { Magnesium } \\
\text { hydroxide }\end{array}$} & P21 & $\begin{array}{l}\mathrm{pH} \text { was adjusted to } 6.8 \text { with } 5 \mathrm{M} \mathrm{NaOH} \text {. The amount of } \mathrm{Mg}(\mathrm{OH})_{2} \text { added was equal to that of the SA present in } \\
\text { the broth }\end{array}$ & 53.96 \\
\hline & $\mathrm{P} 22$ & $\begin{array}{l}\text { The solution pH was not modified after adding the extra acids, the amount of } \mathrm{Mg}(\mathrm{OH})_{2} \text { was } 2.5 \text { times the one } \\
\text { of SA }\end{array}$ & 75.10 \\
\hline \multirow[t]{2}{*}{ Ammonia } & P31 & $\mathrm{pH}$ was adjusted to 6.8 with $5 \mathrm{M} \mathrm{NaOH}$, and titrated with $25 \%(\mathrm{w} / \mathrm{w})$ ammonia-containing solution to $\mathrm{pH} 11$ & 83.58 \\
\hline & P32 & $\begin{array}{l}\text { The } \mathrm{pH} \text { of the solution was not modified after adding the extra acids and titrated with the same amount of } \\
\text { ammonia as in P31 }\end{array}$ & 58.61 \\
\hline
\end{tabular}
are both present in the solution, succinate has a lower tendency to precipitate with calcium.

Table 1. Summary of operating conditions and SA recovery for the performed experiments. 

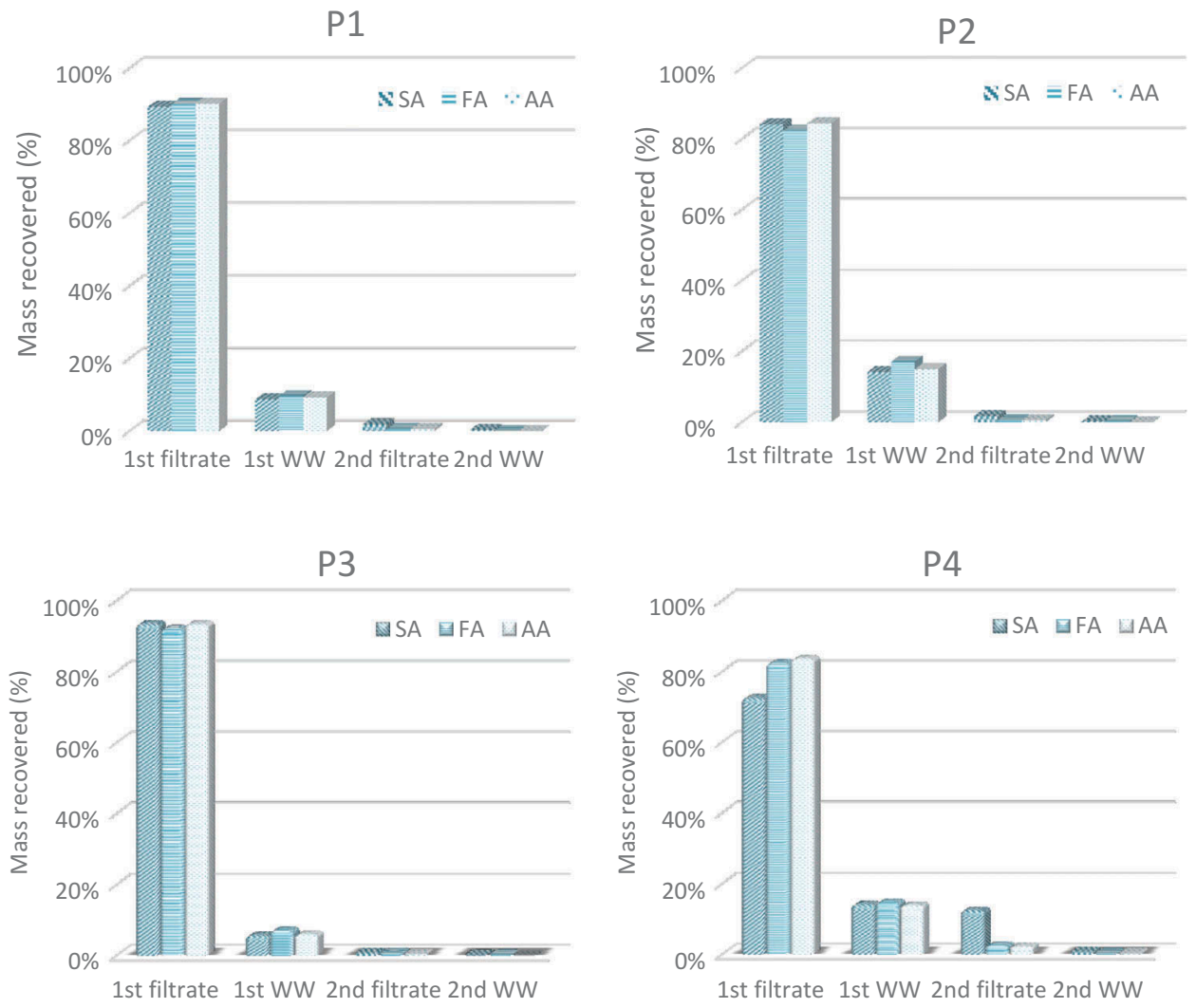

Figure 2. Percentages of the recovered acid masses during the $\mathrm{Ca}(\mathrm{OH})_{2}$ precipitation process for the first set of experiments (P1-P4).

The HPLC analyses showed that the individual concentrations of glucose, sucrose and fructose were all below $1.0 \mathrm{~g} / \mathrm{L}$ (total sugar concentration of $0.5 \mathrm{~g} / \mathrm{L}$ ), which was anticipated since the SA fermentation stops due to sugar depletion. When sulphuric acid was added to the dissolved filter cake, the remaining sugars were dehydrated in a reaction that produces carbon and water, ${ }^{[37]}$ which practically eliminated them in the second filtrate (the total sugar concentration was below $0.1 \mathrm{~g} / \mathrm{L}$ ).

A second set of experiments was designed taking as a base experiment $\mathrm{P} 4$. In this case, the effect of temperature was evaluated, performing the first filtration after cooling the fermentation broth supernatant down to $4^{\circ}$ C. ${ }^{[27]}$ It was also decided to omit the first washing of the precipitate formed and to increase the time between the addition of the $\mathrm{Ca}(\mathrm{OH})_{2}$ slurry and the subsequent filtration so the flasks were cooling during 16 hours before performing the first filtration.

Another variable that was investigated was the effect of the added amount of $\mathrm{Ca}(\mathrm{OH})_{2}$. Dedicated experiments were performed adding 5 and 10 times the amount of $\mathrm{Ca}(\mathrm{OH})_{2}$ supplied in experiment $\mathrm{P} 4$. Finally, to evaluate the possible precipitation interference impact of carob pod ingredients present, two experiments (P9 and P10) were performed using the model solution described in the Materials section. The summary of the conditions applied for this second set of experiments (P5-P10) is presented in Table 1.

By employing the concentrations measured by HPLC, the recovery of each acid was calculated. As can be observed in Fig. 3, the biggest SA recovery occurred in the first filtrate, although there was still some recovery associated with the second filtrate. The increase in the SA recovered from the second filtrate ranged from $16 \%$ in experiment $\mathrm{P} 8$ to $33 \%$ in experiment P9. The lowest recovery was obtained in experiment $\mathrm{P} 8$, which was the only experiment where $\mathrm{NaOH}$ was added, suggesting that the presence of additional sodium ions interferes with the reaction of calcium ions with the succinate, thus diminishing its recovery. Indeed, the difference in recovery between experiments P7 and P8, which differ in the addition of sodium hydroxide, is approximately $10 \%$. This is the same difference found between experiments $\mathrm{P} 1$ and $\mathrm{P} 4$, which difference is also due to the presence of sodium, indicating a consistent decrease in SA recovery when sodium is present in the solution.

Another interesting finding emerged comparing experiments $\mathrm{P} 9$ and $\mathrm{P} 10$, for which the only difference was that in P10 the solution was left for cooling at $4^{\circ} \mathrm{C}$ 
overnight before performing the first filtration. Since the "lost" SA in P10's first filtrate was proportionally larger than the SA amount lost in the same step for P9, it can be settled that the cooling-down step was not helpful to increase the degree of SA recovery.

Among the experiments performed with a real fermentation broth ( $\mathrm{P} 5-\mathrm{P} 8)$, the highest second filtrate recovery of SA was obtained in P7 (26.7\%), which used 10 times the amount of $\mathrm{Ca}(\mathrm{OH})_{2}$ supplied to experiment P4. However, this percentage was very close to the $26.3 \%$ of SA recovery obtained for the same stage in experiment $\mathrm{P} 5$, which indicates that a large excess of calcium is not a determining factor to increase the degree of SA recovery. This $0.4 \%$ difference

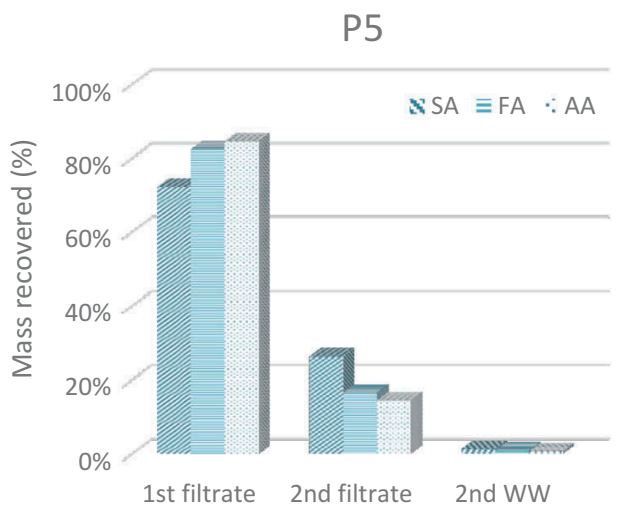

P7

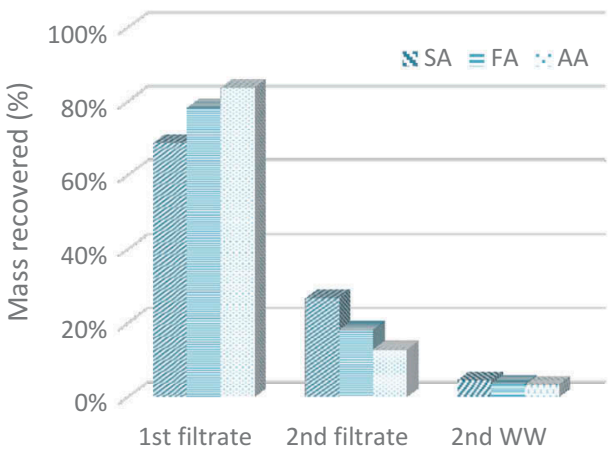

P9

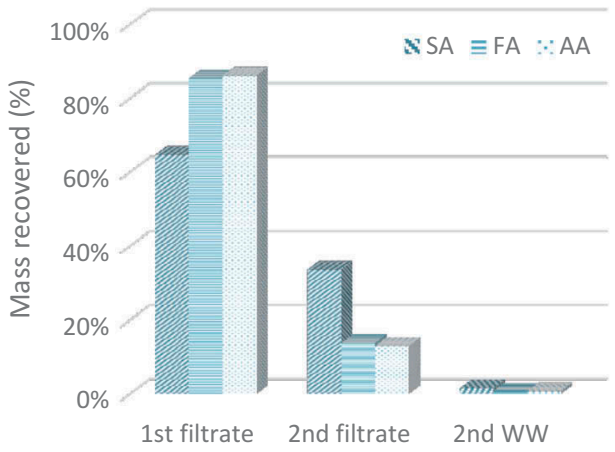

in SA recovery suggests a high reproducibility of the results obtained, since experiments P5 and P7 differ only in the amount of calcium hydroxide added.

Despite the slight improvement in this new set of experiments, higher SA recoveries are desirable. Therefore, additional experiments (P11-P13; see Table 1) included an intermediate agitation step before performing the first filtration. ${ }^{[22]}$ This was performed by placing the flasks on a shaker at $37^{\circ} \mathrm{C}$, where they were kept under agitation at $200 \mathrm{rpm}$ during 20 hours. However, the results for this set of experiments (Fig. 4a) showed SA recoveries in the second filtrate of $28.7 \%$ for P11, $24.5 \%$ for P12 and $23.3 \%$ for $\mathrm{P} 13$, which were very similar to the results obtained in the previous set of experiments (P5-P10).

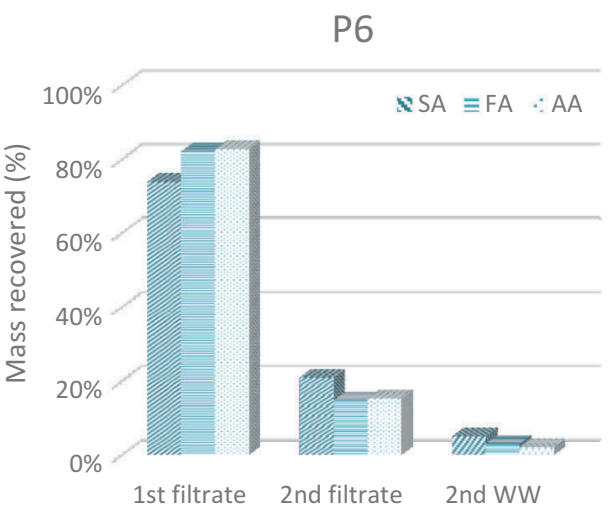

P8

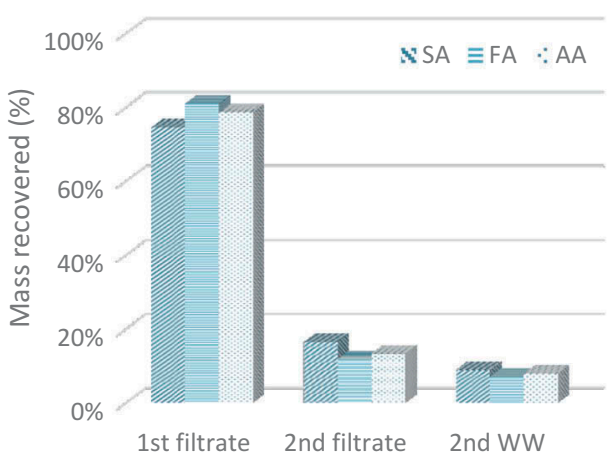

P10

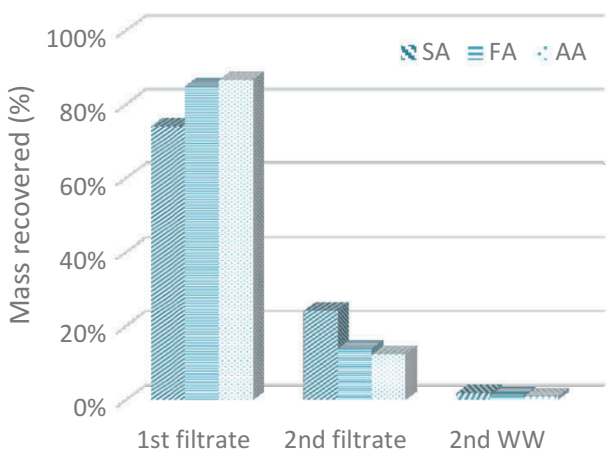

Figure 3. Percentages of the recovered acid masses during the $\mathrm{Ca}(\mathrm{OH})_{2}$ precipitation process for the second set of experiments (P5-P10). 

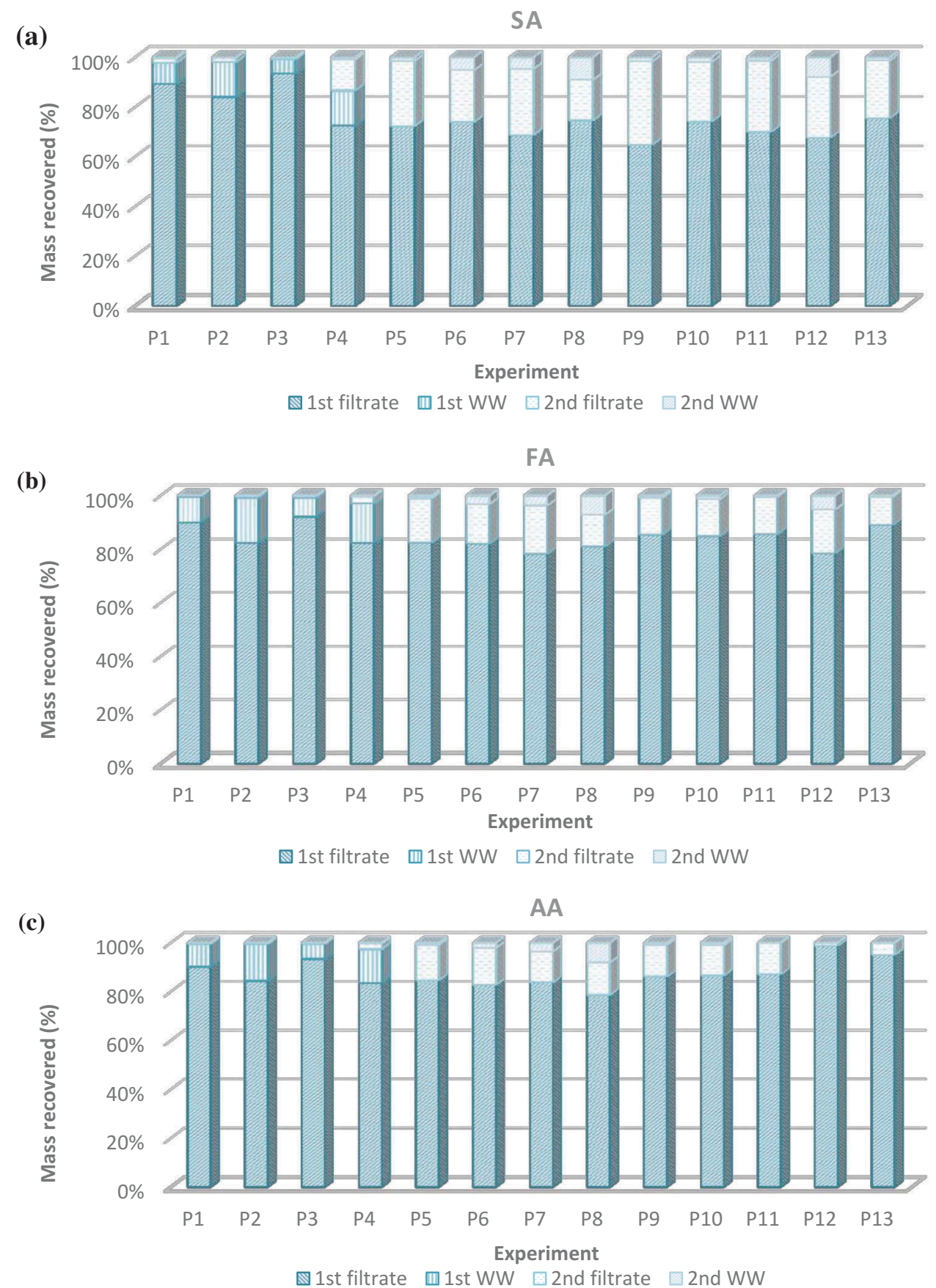

Figure 4. Succinic (a), formic (b) and acetic (c) acids recoveries after each stage of precipitation with $\mathrm{Ca}(\mathrm{OH})_{2}$ for the experiments performed.

The results for all $\mathrm{Ca}(\mathrm{OH})_{2}$ precipitation experiments are shown in Fig. 4. As can be observed in Fig. $4 \mathrm{a}$, the highest succinate recovery $(33.7 \%)$ corresponded to experiment $\mathrm{P} 9$, which was performed with a model solution and without any $\mathrm{pH}$ adjustment (initial $\mathrm{pH}$ equal to 3.68). With an approximately $5.0 \%$ less recovery, the second best result corresponded to experiment P11. These recoveries are in agreement with the $36 \%$ recovery obtained by Luque et al. when employing a modified calcium precipitation method. ${ }^{[22]}$ The results obtained indicate that employing $\mathrm{Ca}(\mathrm{OH})_{2}$ as an SA precipitant in carob pod-based fermentation broths is not an efficient method. To be improved, the first filtrate could be eventually recycled to the fermentation vessel, as suggested by Datta et al. ${ }^{[20]}$

Regarding the recoveries of the other two carboxylic acids, Figs. $4 \mathrm{~b}$ and $4 \mathrm{c}$ show that practically in all experiments, around $80 \%$ of FA and AA was removed in the first filtrate, a higher percentage than for SA, which means that their preferential removal takes place. When 
the first filter cake was washed (P1-P4), the remaining FA and AA were eliminated in the first WW, but in the rest of the experiments, they reached the product stream (second filtrate), so the calculated purity of SA in the referred stream was around $60 \%(\mathrm{w} / \mathrm{w})$ on a dry basis.

\section{Precipitation with magnesium hydroxide}

Contrary to the $\mathrm{Ca}(\mathrm{OH})_{2}$ precipitation technique, where multiple experiments were performed aiming at eventually achieving the recoveries mentioned in the patent by Datta et al., ${ }^{[20]}$ in the case of the technique with $\mathrm{Mg}$ $(\mathrm{OH})_{2}$ only two experiments were performed since by following a procedure similar to the one reported by De Haan et al., ${ }^{[32]}$ close SA recoveries were obtained.

Composition analysis of the redissolved crystals only resulted positive for SA. Sugar absence can be explained, as in the previous section, by their dehydration reaction with acid (in this case hydrochloric acid) and the subsequent formation of carbon. ${ }^{[37]}$ The absence of FA and AA could be explained by their high volatilities, which have caused them to evaporate together with water during the concentration process.

The SA recovery was calculated for the remaining liquid and the redissolved precipitate, and the results obtained are presented. As can be observed in Table 2, for both experiments, the SA recovered in the precipitate was more than $50 \%$ of the amount originally present, being $54 \%$ and $75 \%$ for P21 and P22, respectively. Additionally, the calculated SA purities in the precipitate were $21.9 \%$ for $\mathrm{P} 21$ and $13.3 \%$ for $\mathrm{P} 22$, and the precipitate did not contain either sugars or other carboxylic acids. Mass balances were performed for both experiments, resulting in $8.1 \%(\mathrm{P} 21)$ and $6.2 \%(\mathrm{P} 22)$ differences between the original amount of SA in the fermentation broth and the sum of the SA recovered from both crystals and the remaining solution.

These results are notable, especially when compared to those obtained in the experiments with calcium hydroxide. According to these recoveries, it proved highly beneficial to perform all the neutralization with $\mathrm{Mg}(\mathrm{OH})_{2}$ (and therefore employ a higher amount of it), instead of previously titrating the fermentation broth with another base, such as $\mathrm{NaOH}$. De Haan et al. ${ }^{[32]}$ reported SA recoveries of $86 \%$ in the case of using $\mathrm{Mg}$ $(\mathrm{OH})_{2}$ as a precipitant agent. Although these values are

Table 2. Percentage of succinic acid recovered in the magnesium hydroxide and ammonia precipitation experiments.

\begin{tabular}{lcccc}
\hline & \multicolumn{2}{c}{ Magnesium hydroxide } & \multicolumn{2}{c}{ Ammonia } \\
\hline Experiment & P21 & P22 & P31 & P32 \\
\hline Crystals & $54.0 \%$ & $75.1 \%$ & $83.6 \%$ & $58.6 \%$ \\
Liquid & $46.0 \%$ & $24.9 \%$ & $16.4 \%$ & $41.4 \%$ \\
\hline
\end{tabular}

higher than the ones obtained in the present study, it must be considered that the values reported by ${ }^{[32]}$ were for model solutions that only contained the substances of interest. It seems reasonable to anticipate lower SA recoveries and lower purities of the precipitate when a real fermentation broth, containing a variety of substances, is treated. Therefore, the results obtained in the present study clearly show that $\mathrm{Mg}(\mathrm{OH})_{2}$ is a potentially good candidate for the recovery of SA from carob pod-based fermentations. However, the magnesiumbased precipitation requires heating of the solution to achieve complete salt dissolution, which should be taken into consideration for the cost analysis.

\section{Precipitation with ammonia}

The potential of using ammonia for SA recovery has been evaluated performing experiments P31 and P32 (Table 1). As previously performed, the SA recoveries were calculated for the remaining liquid and for the redissolved precipitate, and are presented in Table 2. The SA recovery was similar to the one obtained in the magnesium-based process (83.6 and $58.6 \%$ for P31 and P32, respectively). The composition analysis showed that, as in the magnesium-based process, the redissolved precipitate only contained SA among the analysed compounds (carboxylic acids and sugars).

It appears that titration of the fermentation broth with $\mathrm{NaOH}$ before adding the ammonia solution did not affect the process performance, since the highest SA recovery was obtained in experiment P31. However, the precipitation process yielded better results for experiment P32 since the precipitate purity was $48.7 \%$, compared to $14.1 \%$ for $\mathrm{P} 31$, the former being the highest value obtained in all the precipitation tests performed. The mass balances for experiments P31 and P32 resulted, respectively, in 5.9 and $10.4 \%$ differences between the original SA mass present in the solutions compared to the SA mass recovered at the end of the experiments.

Yedur et al. ${ }^{[34]}$ employed ammonia as an SA precipitant using a real fermentation broth, although they did not clearly indicate the source of carbohydrates that had served as a feed, obtaining an SA recovery of $78 \%$. In the present study, the obtained SA recovery of $83.6 \%$ (experiment P31) was noticeably higher, thus indicating that ammonia is a promising precipitant for SA recovery from carob pod-based fermentation broths. The diammonium sulphate fraction, which still contains a considerable amount of SA, can be directly used as fertilizer or thermally cracked into ammonia and ammonium bisulphate. Other potential advantages of this route, compared to the calcium-based SA precipitation option, are that ammonia is a relatively cheap 
industrial titrant and that a more valuable salt is coproduced. However, some reservations still remain since ammonia could become inhibitory for the SAproducing microorganisms and the salt co-product needs to be marketed. Additionally, significant amounts of SA still present in the di-ammonium sulphate-containing stream should be recovered to improve the overall process yield and economy. ${ }^{[2]}$

\section{Comparison of the precipitation techniques}

Taking into account the promising results obtained with $\mathrm{Mg}(\mathrm{OH})_{2}$ and ammonia, it was decided to compare the process performance not only on the basis of SA recovery, but also in terms of process sustainability (green) indicators such as EF and MI. The SA recoveries for the best cases obtained in each of the three precipitation techniques studied are presented in Fig. 5. As can be seen, the highest SA recovery was achieved through precipitation with ammonia, followed by the precipitation with magnesium hydroxide. The lowest SA recoveries were achieved with calcium hydroxide.

To determine and compare the process sustainability indicators, the following assumptions were made.

- Since all experiments were performed with identical initial volumetric amounts of fermentation broth, all calculations were performed without considering it as an input to the downstream process. As is common practice, ${ }^{[36]}$ water was not considered in the calculations.

- For the ammonia and magnesium precipitation experiments, only the dry mass corresponding to SA in the precipitates formed was considered as product and the mass of the rest of the precipitate was considered as waste. Additionally, the liquid phase, from which the precipitates were recovered at the end of the experiments, was considered as waste.

For the calcium precipitation experiments, since the final product consisted of a diluted solution of succinic and other carboxylic acids, only the actual mass of SA was considered. As can be observed (Fig. 6), the EF value varied widely from 300 for experiment P1 to 9 for experiment P11. These EF numbers are within the range presented by Pinazo et al. ${ }^{[31]}$ for the production of SA from natural carbohydrates.

As mentioned, the higher the EF value, the higher is the associated negative environmental impact; therefore, the best results in terms of this indicator were obtained for experiments P11, P5 and P13.

Regarding the precipitation processes $\mathrm{MI}$, the best result was obtained for experiment P11 $(\mathrm{MI}=12)$, followed by P5 and P22 (MI equal to 14 and 15, respectively). According to this parameter, it appears that magnesium hydroxide precipitation is the best technique among the three techniques that were evaluated.

A preliminary economic analysis was also performed for the experiments with the highest SA recovery of each technique. For each technique, the costs of the chemicals involved obtained from commercial suppliers for industrial-grade purities ${ }^{[38]}$ were taken into account, and the results obtained (see Table 3) showed that the precipitation with magnesium hydroxide would have the lowest cost of the three techniques, less than half the cost for recovering $1 \mathrm{~kg}$ of SA via precipitation with calcium hydroxide. The most expensive method will be precipitation with ammonia, at around five times the cost estimated for the magnesium hydroxide-based technique.

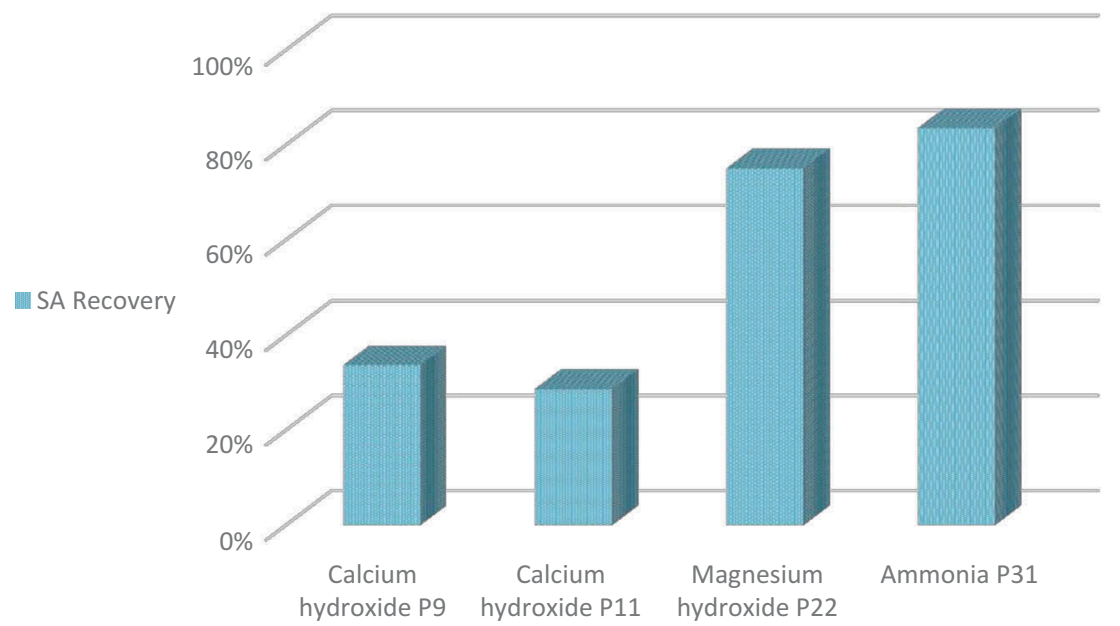

Figure 5. Comparison of succinic acid recoveries for representative cases of the three precipitation techniques. 

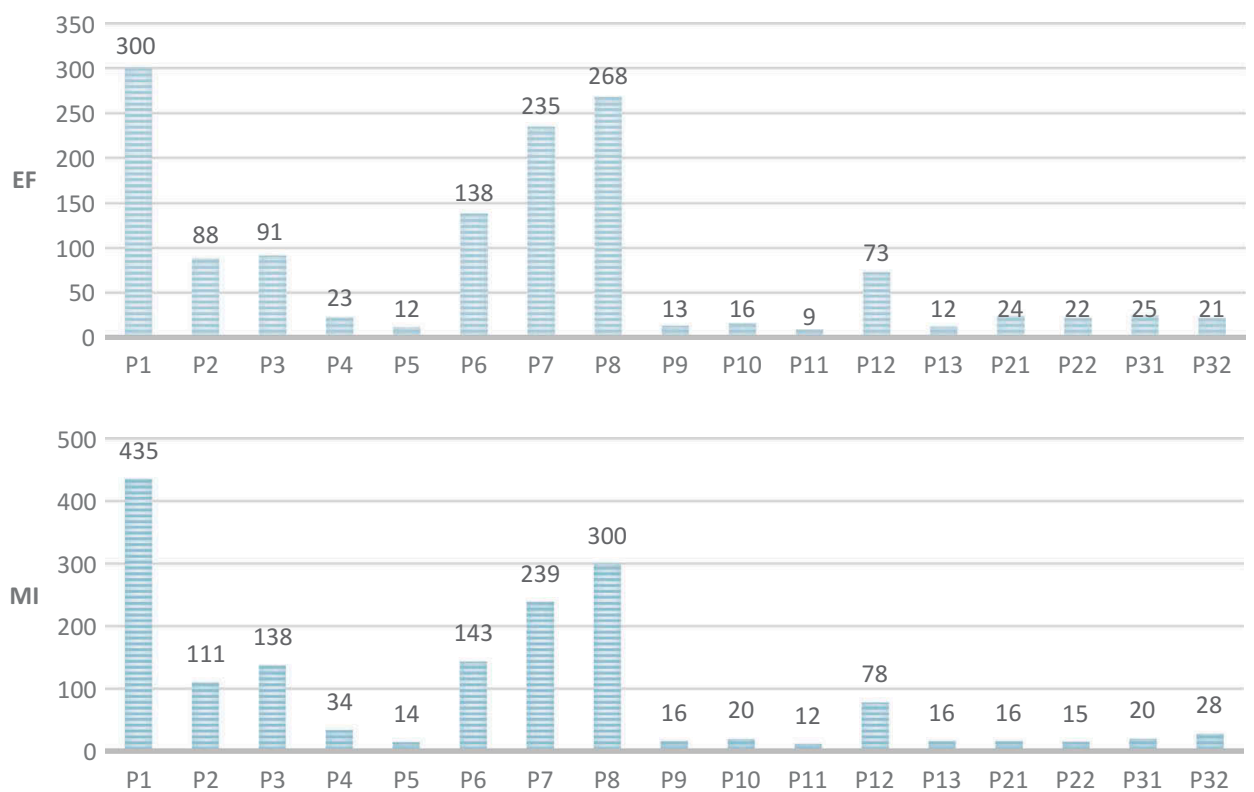

Figure 6. E-Factor and mass intensity (MI) parameters obtained in the experiments.

Table 3. Preliminary operating cost estimation for alternative SA downstream options.

\begin{tabular}{lc}
\hline Method & Cost $(€ / \mathrm{kg}$ SA recovered $)$ \\
\hline Precipitation with calcium hydroxide & 6.86 \\
Precipitation with magnesium hydroxide & 2.72 \\
Precipitation with ammonia & 14.30 \\
\hline
\end{tabular}

\section{Conclusion}

- The highest SA recovery (83\%) and purity (48.7\%) were achieved employing ammonia-based downstream.

- Inclusion of an evaporation step eliminated FA and AA present in the broth.

- The lowest EF and MI values were obtained for the magnesium-based downstream strategy, followed by the ammonia-based strategy.

- A preliminary economic analysis suggests that the cost per kg of SA recovered would be significantly lower for the magnesium-based treatment compared to the ammonia-based treatment. Since a reasonably high SA recovery $(75 \%)$ can be achieved by this treatment option, it appears as the most feasible option for carob pod fermentation broths, containing SA as the main product.

It can be anticipated that materials recycle and/or commercialization of by-products will also play an important role when selecting the most appropriate downstream strategy for a defined case. Further SA enrichment/purification can be achieved, depending on the requirements of the specific application, through more selective separation techniques, including chromatography and/or membrane-assisted treatment.

\section{Acknowledgements}

Paulina A. Sosa gratefully acknowledges the European Commission for her grant to join the EM3E program at Universidade NOVA de Lisboa. The authors would like to thank M. Carvalho for supplying carob pod fermentation broths.

\section{Funding}

This work was supported by the Associated Laboratory for Sustainable Chemistry - Clean Processes and Technologies $\mathrm{LAQV}$, which is financed by Portuguese national funds from FCT/MEC [UID/QUI/50006/2013] and co-financed by the ERDF under the PT2020 Partnership Agreement [POCI-010145-FEDER - 007265].

\section{ORCID}

Svetlozar Velizarov (D) http://orcid.org/0000-0002-9446-0897

\section{References}

[1] Zeikus, J.G.; Jain, M.K.; Elankovan, P. (1999) Biotechnology of succinic acid production and markets for derived industrial products. Applied Microbiology and Biotechnology, 51: 545-552.

[2] Jansen, M.L.; van Gulik, W.M. (2014) Towards large scale fermentative production of succinic acid. Current Opinion in Biotechnology, 30: 190-197. 
[3] Erickson, B.; Nelson, J.E.; Winters, P. (2012) Perspective on opportunities in industrial biotechnology in renewable chemicals. Biotechnology Journal, 7: 176-185.

[4] Sauer, M.; Porro, D.; Mattanovich, D.; Branduardi, P. (2008) Microbial production of organic acids : expanding the markets. Trends in Biotechnology, 26: 100-108. DOI: 10.1016/j.tibtech.2007.11.006.

[5] Werpy, T.; Petersen, G.; Aden, A.; Bozell, J.; Holladay, J.; White, J.; Manheim, A. (2004) Top Value Added Chemicals from Biomass, Vol. 1. Results of Screening for Potential Candidates from Sugars and Synthesis Gas; U.S. Department of Energy: Oak Ridge, USA.

[6] Patel, M.; Crank, M.; Dornburg, V.; Hermann, B.; Roes, L.; Hüsing, B.; Overbeek, L.; Terragni, F.; Reccia, E. (2006) Medium and Long-Term Opportunities and Risks of the Biotechnological Production of Bulk Chemicals from Renewable Resources - the Potential of White Biotechnology the BREW Project; Technical report; Utrecht University: Utrecht, The Netherlands.

[7] Bechthold, I.; Bretz, K.; Kabasci, S.; Kopitzky, R.; Springer, A. (2008) Succinic acid: a new platform chemical for biobased polymers from renewable resources. Chemical Engineering Technology, 31: 647-654.

[8] Blankschien, M.D.; Clomburg, J.M.; Gonzalez, R. (2010) Metabolic engineering of Escherichia coli for the production of succinate from glycerol. Metabolic Engineering, 12: 409-419.

[9] Beauprez, J.J.; Mey, M.; De Soetaert, W.K. (2010) Microbial succinic acid production : natural versus metabolic engineered producers. Process Biochemistry (Barking, London, England), 45: 1103-1114.

[10] Raab, A.M.; Gebhardt, G.; Bolotina, N.; Weuster-Botz, D.; Lang, C. (2010) Metabolic engineering of Saccharomyces cerevisiae for the biotechnological production of succinic acid. Metabolic Engineering, 12: 518-525.

[11] Meynial-Salles, I.; Dorotyn, S.; Soucaille, P. (2008) A new process for the continuous production of succinic acid from glucose at high yield, titer, and productivity. Biotechnology and Bioengineering, 99: 129-135.

[12] Carvalho, M.; Matos, M.; Roca, C.; Reis, M.A.M. (2014) Succinic acid production from glycerol by Actinobacillus succinogenes using dimethylsulfoxide as electron acceptor. New Biotechnology, 31: 133-139.

[13] Zheng, P.; Fang, L.; Xu, Y.; Dong, -J.-J.; Ni, Y.; Sun, Z.H. (2010) Succinic acid production from corn stover by simultaneous saccharification and fermentation using Actinobacillus succinogenes. Bioresource Technology, 101: 7889-7894.

[14] Corona-González, R.I.; Varela-Almanza, K.M.; ArriolaGuevara, E.; Martínez-Gómez, Á.D.J.; Pelayo-Ortiz, C.; Toriz, G. (2016) Bagasse hydrolyzates from Agave tequilana as substrates for succinic acid production by Actinobacillus succinogenes in batch and repeated batch reactor. Bioresource Technology, 205: 15-23.

[15] Carvalho, M.; Roca, C.; Reis, M.A.M. (2014) Carob pod water extracts as feedstock for succinic acid production by Actinobacillus succinogenes 130Z. Bioresource Technology, 170: 491-498.
[16] Manso, T.; Nunes, C.; Raposo, S.; Lima-Costa, M.E. (2010) Carob pulp as raw material for production of the bio-control agent P. agglomerans PBC-1. Journal of Industrial Microbiology and Biotechnology, 37: 11451155.

[17] Carvalho, M.; Roca, C.; Reis, M.A.M. (2016) Improving succinic acid production by Actinobacillus succinogenes from raw industrial carob pods. Bioresource Technology, 218: 491-497.

[18] Pateraki, C.; Patsalou, M.; Vlysidis, A.; Kopsahelis, N.; Webb, C.; Koutinas, A.A.; Koutinas, M. (2016) Actinobacillus succinogenes: advances on succinic acid production and prospects for development of integrated biorefineries. Biochemical Engineering Journal, 112: 285-303.

[19] Wang, C.; Ming, W.; Yan, D.; Zhang, C.; Yang, M.; Liu, Y.; Zhang, Y.; Guo, B.; Wan, Y.; Xing, J. (2014) Novel membrane-based biotechnological alternative process for succinic acid production and chemical synthesis of bio-based poly (butylene succinate). Bioresource Technology, 156: 6-13.

[20] Datta, R.; Glassner, D.A.; Jainf, M.K.; Vick Roy, J. Fermentation and purification process for succinic acid. U.S. Patent 5,168,055, December 1, 1992.

[21] Kurzrock, T.; Weuster-Botz, D. (2010) Recovery of succinic acid from fermentation broth. Biotechnology Letters, 32: 331-339.

[22] Luque, R.; Lin, C.S.K.; Du, C.; Macquarrie, D.J.; Koutinas, A.; Wang, R.; Webb, C.; Clark, J.H. (2009) Chemical transformations of succinic acid recovered from fermentation broths by a novel direct vacuum distillation-crystallisation method. Green Chemistry : an International Journal and Green Chemistry Resource : GC, 11: 193-200.

[23] Staszak, K.; Woźniak, M.J.; Karaś, Z.A.; Staniewski, J.; Prochaska, K. (2013) Application of nanofiltration in the process of the separation of model fermentation broths components. Polish Journal of Chemical Technology, 15: 1-4.

[24] Kang, S.H.; Chang, Y.K. (2005) Removal of organic acid salts from simulated fermentation broth containing succinate by nanofiltration. Journal of Membrane Science, 246: 49-57.

[25] Kim, B.; Hong, Y.; Hong, W. (2004) Effect of salts on the extraction characteristics of succinic acid by predispersed solvent extraction. Biotechnology and Bioprocess Engineering : BBE, 9: 207-211.

[26] Sun, Y.; Yan, L.; Fu, H.; Xiu, Z. (2014) Salting-out extraction and crystallization of succinic acid from fermentation broths. Process Biochemistry (Barking, London, England), 49: 506-511.

[27] Li, Q.; Wang, D.; Wu, Y.; Li, W.; Zhang, Y.; Xing, J.; $\mathrm{Su}, \mathrm{Z}$. (2010) One step recovery of succinic acid from fermentation broths by crystallization. Separation and Purification Technology, 72: 294-300.

[28] Berglund, K.A.; Elankovan, P.; Glassner, D.A. Carboxylic acid purification and crystallization process. U.S. patent 5,034,105, July 23, 1991.

[29] Sosa, P.A.; Roca, C.; Velizarov, S. (2016) Membrane assisted recovery and purification of bio-based succinic 
acid for improved process sustainability. Journal of Membrane Science, 501: 236-247.

[30] Carlson, A.; Coggio, B.; Lau, K.; Mercogliano, C.; Millis, J. (2016) In: Chemicals and Fuels from BioBased Building Blocks. Cavani, F.; Albonetti, S.; Basile, F.; Gandini, A. (Eds.), Wiley-VCH Verlag GmbH \& Co. KGaA, : Weinheim, 173-190.

[31] Pinazo, J.M.; Domine, M.E.; Parvulescu, V.; Petru, F. (2014) Sustainability metrics for succinic acid production: a comparison between biomass-based and petrochemical routes. Catalysis Today, 239: 17-24.

[32] De Haan, A.B.; Van Breuge, J.; Van Der Weide, P. L.; Jansen, P.P.; Vidal Lancis, J.M. Recovery of carboxilic acid from their magnesium salts by precipitation using hydrochloric acid, useful for fermentation broth work-up. WO patent 025105A1, February 23, 2013.
[33] Berglund, K.A.; Yedur, S.; Dunuwila, D.D. Succinic acid production and purification. U.S. Patent 5,958,744, September 28, 1999.

[34] Yedur, S.; Berglund, K.A.; Dunuwila, D.D. Succinic acid production and purification. U.S. Patent 6,265,190 B1, July 24, 2001.

[35] Henderson, R.K.; Jiménez-González, C.; Preston, C.; Constable, D.J.C.; Woodley, J.M. (2008) EHS \& LCA assessment for 7-ACA synthesis. Industrial Biotechnology, 4: 180-192.

[36] Sheldon, R.A.; Sanders, J.P.M. (2014) Toward concise metrics for the production of chemicals from renewable biomass. Catalysis Today, 239: 3-6.

[37] Shakhashiri, B.Z. (1983) Chemical Demonstrations: A Handbook for Teachers of Chemistry; The University of Wisconsin Press: Madison.

[38] Inorganic chemicals. (http://www.alibaba.com/cata logs/products/CID100003732). 